\title{
Gamma Irradiation and Autoclave Sterilization Peat and Compost as the Carrier for Rhizobial Inoculant Production
}

\author{
Panlada Tittabutr ${ }^{1}$, Kamonluck Teamthisong ${ }^{2}$, Bancha Buranabanyat ${ }^{1}$, Neung Teaumroong ${ }^{1} \&$ Nantakorn \\ Boonkerd $^{1}$ \\ ${ }^{1}$ School of Biotechnology, Suranaree University of Technology, Nakhon Ratchasima, Thailand \\ ${ }^{2}$ The Center for Scientific and Technological Equipment, Suranaree University of Technology, Nakhon Ratchasima, \\ Thailand \\ Correspondence: Nantakorn Boonkerd, School of Biotechnology, Suranaree University of Technology, Nakhon \\ Ratchasima, Thailand. Tel: 66-4422-4501. E-mail: nantakon@sut.ac.th
}

Received: August 1, 2012 Accepted: August 28, 2012 Online Published: November 15, 2012

doi:10.5539/jas.v4n12p59 URL: http://dx.doi.org/10.5539/jas.v4n12p59

\begin{abstract}
Rhizobium is a biofertilizer for leguminous crops. To formulate this form of fertilizer, the suitable sterilization processes of carrier are important. Therefore, the aim of this research was to elucidate the process of gamma irradiation and autoclaving on peat and compost based carriers for rhizobial inoculant production. Carriers with $10 \%$ moisture content packing in polyethylene bag could be efficiently sterilized by irradiation at 10-20 kGy, or by autoclaving with tyndallization approach (autoclaving two times in a row at $121^{\circ} \mathrm{C}$ for $60 \mathrm{~min}$, with waiting period of 18 hours after each time of autoclaving). The number of Bradyrhizobium sp. PRC008 was in the range of $10^{8}-10^{9} \mathrm{cfu} / \mathrm{g}$ in both irradiated and autoclaved peat after 6 months storage. However, the numbers of bradyrhizobial cell were reduced in compost sterilized by both methods after one month storage. These results indicated that carrier material had an important influence on inoculant quality, while sterilization processes using gamma irradiation and autoclaving with tyndallization approach could be used for efficient rhizobial inoculant production with peat based carrier.
\end{abstract}

Keywords: autoclaving, gamma irradiation, rhizobial inoculant, sterilization, tyndallization

\section{Introduction}

Using rhizobial inoculant is a clean technology for sustainable agriculture. Rhizobial inoculants have been used as an environmental friendly source of nitrogen fertilizer for several decades to reduce putting chemical nitrogen fertilizer into the soil, as well as the cost of legume production. There are several forms of rhizobial inoculant available in the market, including solid or liquid forms that can maintain the survival of effective rhizobia at the level of $10^{8}$ cells/g for at least 6 months (Stephens \& Rask, 2000). Even though the liquid form of rhizobial inoculants is applied in the production process more easily than solid form, the survival of rhizobial cell in liquid inoculants depends on strain of rhizobia and polymeric additive substance incorporated into liquid inoculants formulation (Tittabutr et al., 2007). Thus, solid inoculants, especially those using peat-based carrier, are still popular for biofertilizer inoculant production because peat could support the survival of bacteria in long term storage (Kishore et al., 2005; Okon \& Labandera-Gonzalez, 1994). However, peat is limited in many countries including Thailand, so it is necessary to find carriers that are locally available for commercial scale production. The appropriate material to be used as a carrier in rhizobial or biofertilizer inoculant production should be non-toxic material, have good water holding capacity, support bacterial growth and survival, be easily prepared in powder form, and have nearly neutral pH (Albareda et al., 2008; Khavazi et al., 2007; Smith, 1992). Several materials have been tested as an alternative carrier source for rhizobial inculants, such as soil, coal, vermiculite, perlite, attapulgite, sepiolite, amorphous silica, cork compost, grape bagasse, and other plant composts (Albareda et al., 2008; Ferreira \& Castro, 2005; Khavazi et al., 2007). However, the quality of inoculant is varied according to the physicochemical and biological properties of material as well as the sterilization method applied to carrier (Khavazi et al., 2007; Swelim et al., 2010). Since contaminant microorganism is the main problem that affects the quality and shelf-life of rhizobial inoculant, sterilized carrier is necessary to be accomplished prior injection of the pure culture of rhizobia into carrier. 
Commercial rhizobial carriers are normally sterilized by gamma irradiation or autoclaving, depending on the accessibility and availability of instrument. Mechanism of sterilization by autoclaving is based on the wet killing of microorganisms under high temperature $\left(121^{\circ} \mathrm{C}\right)$ and high pressure $\left(15\right.$ ponds/inch $\left.{ }^{2}\right)$ for a period of time, depending on the size and the composition of material. However, the problem of spore forming microorganisms contaminant remains in the carrier after autoclaving is the main problem of using this sterilization method. While the mechanism of sterilization by gamma irradiation is due to the direct breakdown of double strand DNA, or occurring from the ionized water molecules form free radicals and disrupt biological system in the cell (Hansen \& Shaffer, 2001). Sterilization of rhizobial carrier should consider in the physical and chemical changes of material which should not produce or release toxic substances and not destroy the available nutrients in material (Strijdom \& van Rensburg, 1981). Another consideration is the efficiency of sterilization method, since high numbers of contaminating microorganisms significantly reduce the quality of rhizobial inoculant. Although gamma irradiation at high dose rate is more effective than autoclaving, the number of rhizobia in carrier is not significantly different after 6 months storage (Khavazi et al., 2007). The dose required to sterilize carrier varies with the property of material, the density, moisture content, initial contaminating load and packaging configuration. However, higher dose rate of gamma rays may produce higher toxic breakdown product from the carrier material, and some of spore forming microorganisms are still found when storing the carrier for a period of time (Yardin et al., 2000). Although the dose rate more than $50 \mathrm{kGy}$ is usually used for efficient sterilization of carrier, lower dose rate is required for reducing energy and time of sterilization as well as reduce the toxic substances that may be produced when using high dose of gamma irradiation. This study aimed to find out the process of carrier preparation to achieve lowest dose rate that effectively sterilized carrier by gamma irradiation. The factors of carrier moisture content and plastic type container were elucidated. As well as the strategy of killing geminated spore forming microorganism by the application of tyndallization approach with autoclaving sterilization was also determined in order to minimize the contaminating microorganisms in the compost and peat for using as rhizobial carrier in inoculant production.

\section{Method}

\subsection{Carrier Materials}

Two types of carrier, peat and compost, were used throughout the experiments. Peat was derived from Department of Agriculture (DOA), Thailand, while compost was obtained from Suranaree University of Technology. Compost was made from the mixture of agricultural wastes, such as cassava peel, filter cake, chicken dung and cow dung. The $\mathrm{pH}$ of peat and compost was 4.5 and 7.49 , respectively. Both peat and compost were first milled and passed through a 100 -mesh sieve, before the $\mathrm{pH}$ of peat was adjusted to nearly 7.0 by using $\mathrm{CaCO}_{3}$. Peat and compost were sent to Soil Laboratory, School of Plant Production Technology, Suranaree Univeristy of Technology, Thailand to determine the physical and chemical characteristics of carriers according to the standard method.

\subsection{Carrier Preparations}

The moisture contents of carrier were adjusted to 10,20 , and $30 \%$ by using water, and $80 \mathrm{~g}$ of each carrier were packed into $5 \times 8$ (inches $\times$ inches) plastic bag, either using the polyethylene (PE) or polypropylene (PP) bags with a thickness of $0.08 \mathrm{~mm}$ prior to sterilization. Each package had thickness of $0.8 \mathrm{~cm}$. The moisture content of carrier and type of plastic bag container were varied according to each experiment.

\subsection{Carrier Sterilization Procedures}

\subsubsection{Sterilization by Gamma Irradiation}

Carrier packages were sterilized with gamma irradiation at Thailand Irradiation Center, Thailand Institute of Nuclear Technology (Nakhon Na-yok, Thailand). Cobolt-60 was used as a source of radiation. The packages were sterilized with different doses of gamma irradiation at 5, 10, 15, 20, and $25 \mathrm{kGy}$. The dosage received at various depths and locations were measured by using dosimeter to ensure the amount of radiation doses. The gamma irradiated packages were delivered to Suranaree University of Technology within a week for determination of the number of microbial contaminants in carrier after gamma sterilization.

\subsubsection{Sterilization by Autoclaving}

Carriers were moistened to $10 \%$ before packing $80 \mathrm{~g}$ of each carrier into $5 \times 8$ (inches $\times$ inches) of PE bag. The tyndallization approach was applied for carrier sterilization. The autoclave was operated for 2 times in a row at $121^{\circ} \mathrm{C}$ for $60 \mathrm{~min}$, while the waiting period after each time of autoclaving was varied at 18 and $24 \mathrm{~h}$.

\subsection{Microbial Contaminants Enumeration}

The number of microbial contaminants in sterilized carrier package was determined at 1 week after sterilization by aseptically removing $10 \mathrm{~g}$ of carrier from each bag, and carrier was diluted in $90 \mathrm{ml}$ sterilized water, and shaken at 
$200 \mathrm{rpm}$ for $30 \mathrm{~min}$. The sample was 10 -fold serial diluted in sterilized water and plated in duplicate onto plate count agar (PCA) and potato dextrose agar (PDA) for bacteria and molds enumeration, respectively. Colonies were counted after incubation at $28^{\circ} \mathrm{C}$ for 5 days, and calculated as $\log$ number of colony forming unit $(\mathrm{cfu}) / \mathrm{g}$ dry weight carrier. The torn carrier packages were excluded from the experiment.

\subsection{Inoculant Preparation and Storage}

Bradyrhizobium sp. PRC008, obtained from DOA, Thailand has normally been used as an inoculum strain for inoculant production by DOA. This strain was recommended to use with mungbean (Vigna radiata L.) to reduce the use of chemical nitrogen fertilizer. In this study, PRC008 was cultured in a yeast extract mannitol (YEM) broth until late log phase. The culture was diluted 10 times, and $20 \mathrm{ml}$ of diluted culture were aseptically injected into the bag containing $80 \mathrm{~g}$ of sterilized carrier with $20 \%$ of moisture content. Bags were thoroughly kneaded by hands, and the final moisture content of carrier was $40 \%$ at this step. Then, bags were incubated at $28^{\circ} \mathrm{C}$ for 1 week and then left at room temperature $\left(28-30^{\circ} \mathrm{C}\right)$ for 6 months.

\subsection{Enumeration of Rhizobial Cells by Plant Infection Count}

The number of effective Bradyrhizobium sp. PRC008 was determined every month for 6 months after the injection by using plant infection count based on the principle assumptions underlying the most-probable-number (MPN) method (Somasegaran \& Hoben, 1994).

\section{Results and Discussion}

\subsection{Physicochemical Characteristics of Compost}

In order to determine whether the compost had similar properties to peat, the physical and chemical characteristics of compost and peat were determined. The results are shown in Table 1. Peat and compost were much different in $\mathrm{pH}$, organic matter, nitrogen, and phosphorus contents. The $\mathrm{pH}$ of compost was readily in neutral range, which would be suitable for survival of rhizobia, while acidity of peat must be neutralized by using $\mathrm{CaCO}_{3}$. The organic matter of peat was 4.4 times higher than in the compost. The amount of organic matter may contribute to longer survival of rhizobial cells in the carrier. Khavazi et al. (2007) reported that the mixing of perlite with high organic matter containing materials, such as sugarcane bagasse or malt residue could increase the number of bradyrhizobial cell survival at six months storage. Although the organic matter of compost was lower than peat, compost had higher nutrient contents. The high nutrient content was one of the key characteristics of good carrier (Smith, 1992). Compost in this study was made from the mixture of cassava peel, filter cake, chicken dung, and cow dung. However, not all sources of compost material could be used as carrier. Some compost materials, such as grape bagasse, result in a sharp decline of the population of Ensifer (Sinorhizobium) fredii SMH12 and Bradyrhizobium japonicum USDA110 after 15 days storage, probably because high content of phenolic compounds in the compost affects the growth of rhizobial cells (Albareda et al., 2008). Although compost used in this study has several characteristics that indicate its potential as a good carrier for rhizobial inoculant production, the final decision is based on rhizobial cell survival during storage. Thus, the appropriate sterilization methods using gamma irradiation and autoclaving with tyndallization approach, as well as rhizobial survival test in the compost as carrier, were elucidated below by comparing with peat carrier.

Table 1. Physical and chemical properties of peat and compost

\begin{tabular}{lcccccc}
\hline Materials & $\mathrm{pH}$ & Organic matter $(\%)$ & $\mathrm{N}(\%)$ & $\mathrm{P}(\%)$ & $\mathrm{K}(\%)$ & Initial Moisture (\%) \\
\hline Peat & 4.5 & 62.23 & 1.19 & 1.73 & 0.5 & 8.07 \\
Compost & 7.49 & 14.13 & 2.19 & 3.22 & 0.77 & 6.78 \\
\hline
\end{tabular}

Peat was adjusted to $\mathrm{pH} 7.0$ by using $\mathrm{CaCO}_{3}$ before using in the experiments.

\subsection{Factors Affecting the Sterilization Efficiency by Using Gamma Irradiation}

Gamma irradiation is a technique used for sterilization of several products, such as medical and pharmaceutical products, agricultural products, food products or food packages. However, sterilization using gamma irradiation with peat or compost, which have complex carbon-based structure and usually contain high level of contaminating load need to determine the appropriate dose rate and other factors that influence sterilization efficiency. The factor of material moisture contents $(10,20$, and 30\%) and types of plastic container (PP and PE) were examined in order to use lowest dose rate of gamma radiation for sterilization. Due to the limited amount of peat in this experiment, only compost was used to determine the appropriate moisture content of material and packed in PP bag before 
being exposed to gamma radiation. The compost with 10,20 , and $30 \%$ moisture contents could be efficiently sterilized by gamma radiation at dose rate of 10,15 , and $25 \mathrm{kGy}$, respectively (Figure 1). There were no bacteria or molds found in carrier at one week after irradiation when $10 \%$ moisture content was applied with gamma radiation at dose rate of $10 \mathrm{kGy}$, while at the same dose rate the number of molds more than $10 \mathrm{cfu} / \mathrm{g}$ and bacteria more than $10^{4} \mathrm{cfu} / \mathrm{g}$ were detected in the carriers with 20 and $30 \%$ moisture content, respectively. It is interesting that even high thrash dose rate of $20 \mathrm{kGy}$ was applied, the number of bacteria more than $10^{3} \mathrm{cfu} / \mathrm{g}$ remained in the carrier with $30 \%$ moisture (Figure 1). These results revealed the influence of moisture content on gamma irradiation efficiency. The survival ability of these microbial contaminants depends on variations in cell physiology, ability to form spores or cysts, substrate available, as well as environmental factors, such as temperature and moisture (Yardin et al., 2000). High moisture content may increase the bacterial contaminants load prior to sterilization. Moreover, the moisture may also favor the germination of bacterial spores and support the survival of contaminants in moisten carrier.

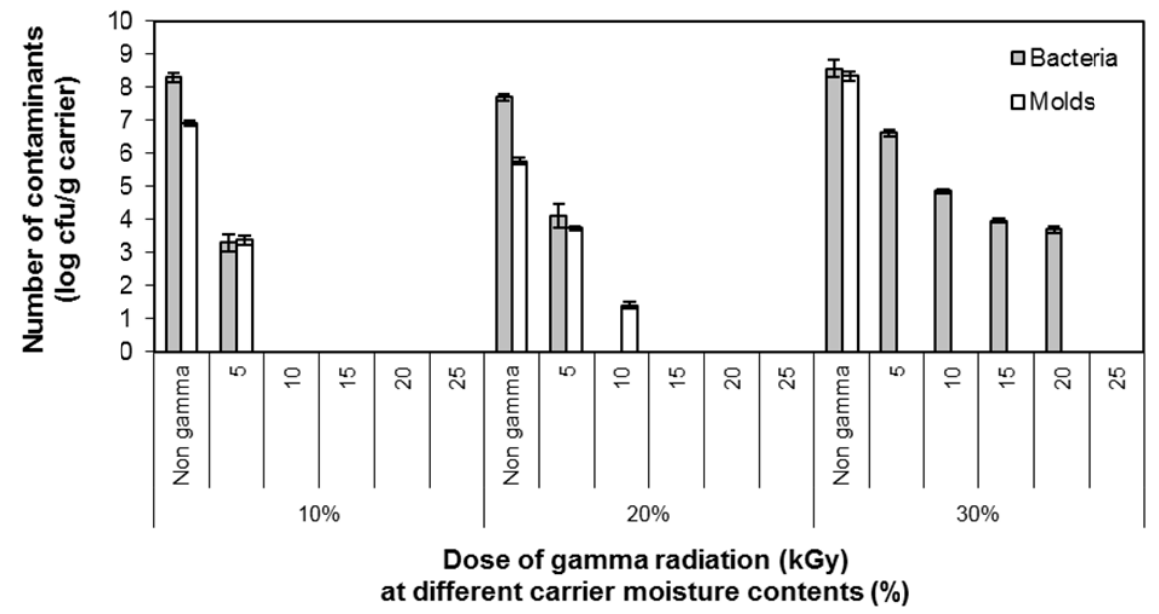

Figure 1. Number of microbial contaminants, bacteria (grey bars) and molds (white bars) remaining in compost with moisture contents of 10,20 , and $30 \%$, and sterilization by gamma irradiation at dose rates of 0 (non gamma), 5, 10, 15, 20, and $25 \mathrm{kGy}$

The types of plastic container were also examined in order to identify durable and available plastic bags in the market that allow the lowest dose rate of gamma radiation for sterilization. Both peat and compost were used in this study by adjusting their moisture content at $10 \%$ prior to gamma radiation. The results show that penetration of radiation through PP bag tended to be better than through PE bag, since lower dose rate of radiation was needed for carrier sterilization. Packing of peat in PP bag allowed the lowest dose rate of $5 \mathrm{kGy}$ for sterilization, while the dose rate of $20 \mathrm{kGy}$ needed to be used for sterilization in PE bag. On the other hand, there were a number of bacterial cells (more than $10^{4} \mathrm{cfu} / \mathrm{g}$ ), and molds (more than $10 \mathrm{cfu} / \mathrm{g}$ ) still remaining in $10 \mathrm{kGy}$ irradiated compost packed in PP and PE bag, respectively (Figure 2). However, PE bags appeared to be more durable than PP bag after gamma irradiation at high doses. Actually, various types of containers could be used for rhizobial inoculant packaging, such as glass bottles, metal cans, hard plastic containers, including low density plastic film, such as PE or PP bags. The good material for inoculant production should provide high moisture retention and sufficient gas exchange for supporting growth and long term survival, and it should be heat-sealed as well (Rodriguez-Navarro et al., 2011). In this experiment, PE bag met the desirable durability to high dose rate of gamma radiation, thus PE bag was used as container for peat and compost in rhizobial survival test after gamma irradiation.

Nevertheless, it is worthy to note that microbial contaminants could be detected in gamma irradiated carriers after storage at room temperature for two months (data not shown). In fact, gamma ray is an effective method for sterilization, since the ionizing radiation could interact directly with charged particles such as DNA, and cause double strand break with matter to cell survival. Moreover, the charged particles and ions destroy the cellular integrity, resulting in spore inactivation and loss of viability (Helfinstine et al., 2005). Ionized water molecules could also form free radicals and disrupt biological systems (Hansen \& Shaffer, 2001). However, gamma 
irradiation could not eliminate all microbial contaminants since some of these microorganisms were sub lethally injured by the irradiation process and were able to repair and replicate themselves if the surrounding conditions, such as nutrient, $\mathrm{pH}$, and moisture, were suitable (Yardin et al., 2000). Although vegetative cells of bacteria are very sensitive to gamma radiation, bacterial spores are more resistant than yeasts or molds (van Gerwen et al., 1999). The longer incubation times may also result in the recovery of injured spore formers (Abshire et al., 1980). Thus, even though the contaminants were not detected in peat or compost after irradiation, a variety of microbial contaminants may recover in the carriers after several weeks. The survivors were mostly spore-forming bacteria and encapsulated microorganisms. The main bacterial species identified in the carriers by Yardin et al. (2000) were Bacillus spp. and actinomycetes, even carriers were exposed to gamma radiation at dose rate more than $50 \mathrm{kGy}$. Although gamma irradiation could not be ensured to kill all of microbial contaminants, the significant reduction of contaminants load could allow high number of rhizobia to remain in the carrier after long term storage when compared with using unsterilized carrier.

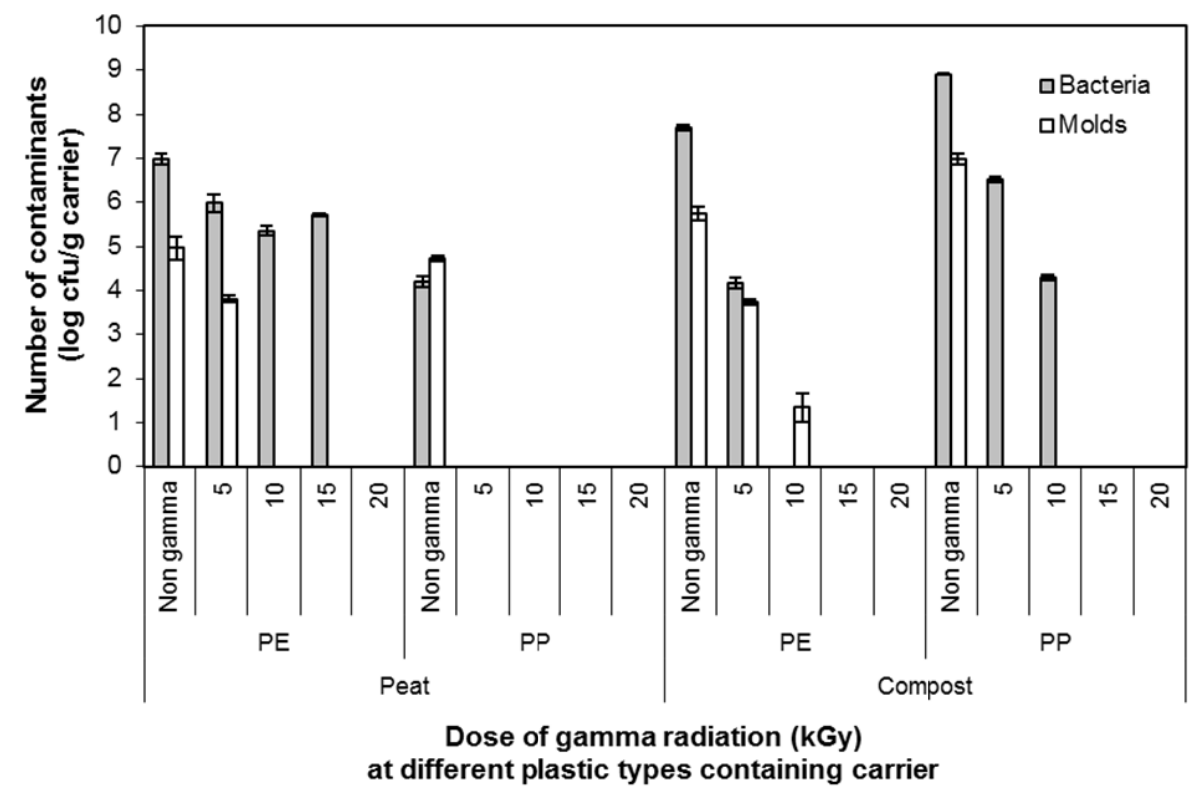

Figure 2. Number of microbial contaminants, bacteria (grey bars) and molds (white bars) remaining in peat or compost packaged in polyethylene (PE) and polypropylene (PP) bag, and sterilization by gamma irradiation at dose rates of 0 (non gamma), 5, 10, 15, and $20 \mathrm{kGy}$

\subsection{Sterilization of Carriers by Autoclaving with Tyndallization Approach}

Although sterilization by gamma irradiation is a useful method in terms of bulk sterilization in prepacked container as well as less time and energy requirement for sterilization, this method is not available in some developing countries. Moreover, some of the spore-forming bacteria withstand the gamma radiation. Thus, the regular sterilization method using autoclaving is another choice for carrier sterilization. The approach of tyndallization process was applied in this study in order to destroy microbial cell and spore forming microorganisms which were present in peat or compost. Tyndallization process was based on thermal inactivation of microorganisms and spores with a heat treatment for double or triple times in the row (Valero \& Salmeron, 2003; Gould, 2006). In this study, carriers with $10 \%$ moisture were autoclaved at $121^{\circ} \mathrm{C}$ for $60 \mathrm{~min}$ two times, while the holding period after each time of autoclaving was varied at 18 and $24 \mathrm{~h}$. Microbial vegetative cells were killed during each time of heat challenge, while the spore forming microorganisms were allowed to germinate during the holding period, and their vegetative cells were eliminated by the second autoclaving. The results showed that molds at $10^{7}-10^{8}$ and $10^{5}-10^{6}$ $\mathrm{cfu} / \mathrm{g}$ carrier were completely eliminated in peat and compost, respectively by autoclaving two times with $18 \mathrm{~h}$ holding period between each time. Nevertheless, bacterial cell around $100 \mathrm{cfu} / \mathrm{g}$ carrier still remained in both carriers by using this method. On the other hand, bacteria and molds were found to survive in peat and compost when $24 \mathrm{~h}$ holding period was applied. The amount of bacteria and molds remained in range of $10-100 \mathrm{cfu} / \mathrm{g}$ peat, which was similar to the number of bacterial cell remain in compost. However, a number of living molds in the compost was higher than that of living bacteria (100-1000 cgu/g carrier). It is possible that the germination and 
spore forming period of bacteria or fungi are different according to their species, thus $24 \mathrm{~h}$ holding time would activate some of microorganism species to fall into spore forming period. Moreover, the response of different species to surrounding environment, such as heat, moisture, $\mathrm{pH}$, and nutrition in each carrier would be the factors that affect the sterilization by using tyndallization approach. The tyndallization-like process using two steps heating separated by holding period under anaerobic condition failed to kill spore-forming Bacillus cereus and $B$. subtilis in dairy product (Brown et al., 1979). However, spores of B. subtilis ATCC6633 were successfully inactivated when tyndallization-like process with two steps heating was applied regardless of heating method used (Cho et al., 1999). Thus, the elimination of spore-forming microorganisms by using autoclaving with tyndallization approach could not certify a complete sterilization of carrier material. The effectiveness of this method significantly depended on species of spore-forming microorganism and physicochemical characteristics of materials. However, the reduction of microbial contaminants should support high number of rhizobia in the carrier during storage time. Thus, two steps autoclaving with $18 \mathrm{~h}$ holding period was applied for both peat and compost as carrier for testing the long term storage of rhizobial inoculants comparing with carriers sterilized with gamma irradiation.

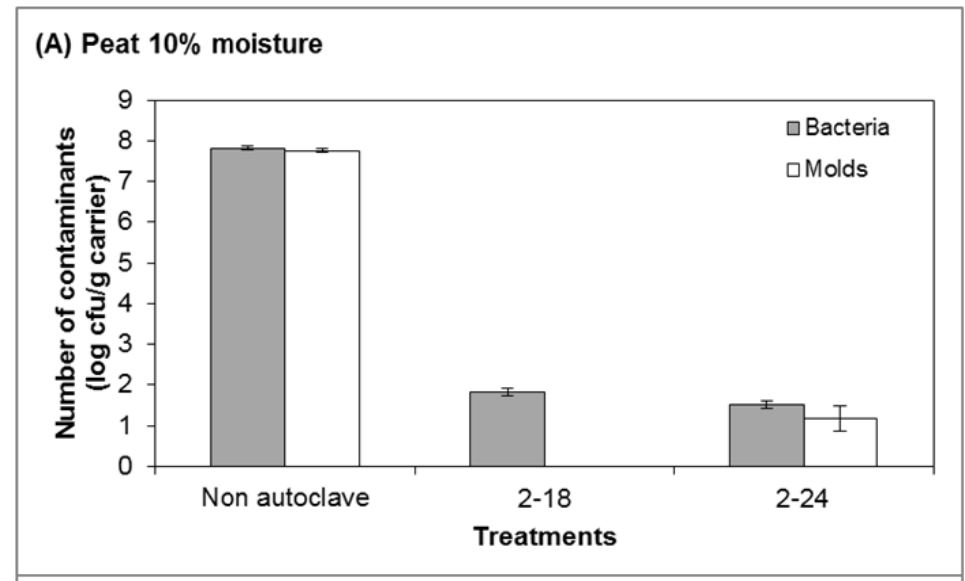

(B) Compost $10 \%$ moisture

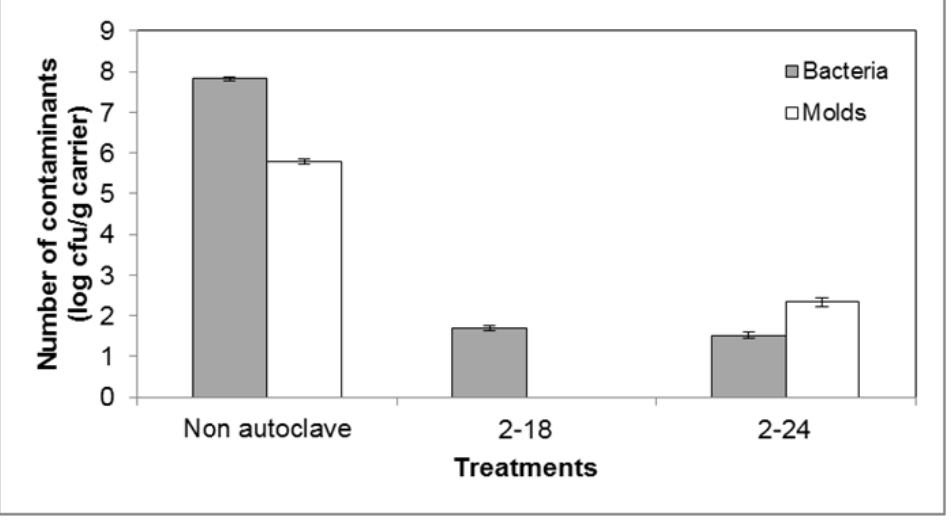

Figure 3. Number of microbial contaminants, bacteria (grey bars) and molds (white bars) remaining in (A) peat and (B) compost without sterilization (non autoclave) and with sterilization by autoclaving two times with the holding period of $18 \mathrm{~h}(2-18)$ and $24 \mathrm{~h}(2-24)$ between each time of sterilization

\subsection{Survival of Bradyrhizobium sp. PRC008 in Sterilized Carriers}

To investigate the possibility of using compost instead of peat, and sterilization methods using gamma irradiation or autoclaving with tyndallization process to minimize the contaminant in carriers, Bradyrhizobium sp. PRC008 was injected into both peat and compost derived from both sterilization methods in order to determine the survival of cell during long term storage at room temperature. The number of cells in the treatments was monitored every month by using MPN method in order to check the nodulation activity of bradyrhizobia after storage. The initial number of bradyrhizobia in both carriers after injection was $10^{6}$ cells/g carrier (Figure 4 ). The results showed that bradyrhizobia could grow and survive well in peat as carrier regardless of sterilization methods. The number of 
cells increased from $10^{6}$ to $10^{8}$ cells/g after one month, and remained more than $10^{8}$ cells $/ \mathrm{g}$ at 6 months storage, which is high enough for effective competition and nodulation of mungbean seed (Figure 4). Thus, the number of contaminants remaining in peat after sterilization by gamma irradiation or autoclaving did not affect bradyrhizobial growth. However, it was not successful to use compost as carrier for bradyrhizobial inoculant. The number of cells increased only 1 magnitude from $10^{6}$ to $10^{7}$ cells/g at one month storage, and sharply decreased at two months storage with no significant difference between gamma irradiation and autoclaving sterilization methods (Figure 4). These results indicated an inappropriate condition for bradyrhizobial growth and survival in the compost. An inappropriate condition might result from a significant change in chemical composition of the compost or a release of some toxins after the sterilization by either gamma irradiation or two steps autoclaving (Strijdom \& van Rensburg, 1981). Although gamma irradiation generated lesser heat than autoclaving, some particular chemical compositions might be affected by gamma radiation directly. Since compost used in this study was derived from the mixture of cassava peel, filter cake, chicken dung, and cow dung, it should be note that not all types of compost could be used as carrier. As reported by Albareda et al. (2008), the compost made from grape bagasse also caused sharply reduces the number of rhizobia. Cassava peels contain toxic compound in form of cyanogenicglucosides (Oboh, 2006). It could be possible that some level of toxic compound might remain in the compost used in this experiment. An inappropriate condition might also be the result from some spore-forming microorganisms that still remains in the compost after sterilization. These spore-forming microorganisms may produce toxin or compete for nutrients available in carrier and finally reduce the number of bradyrhizobia.

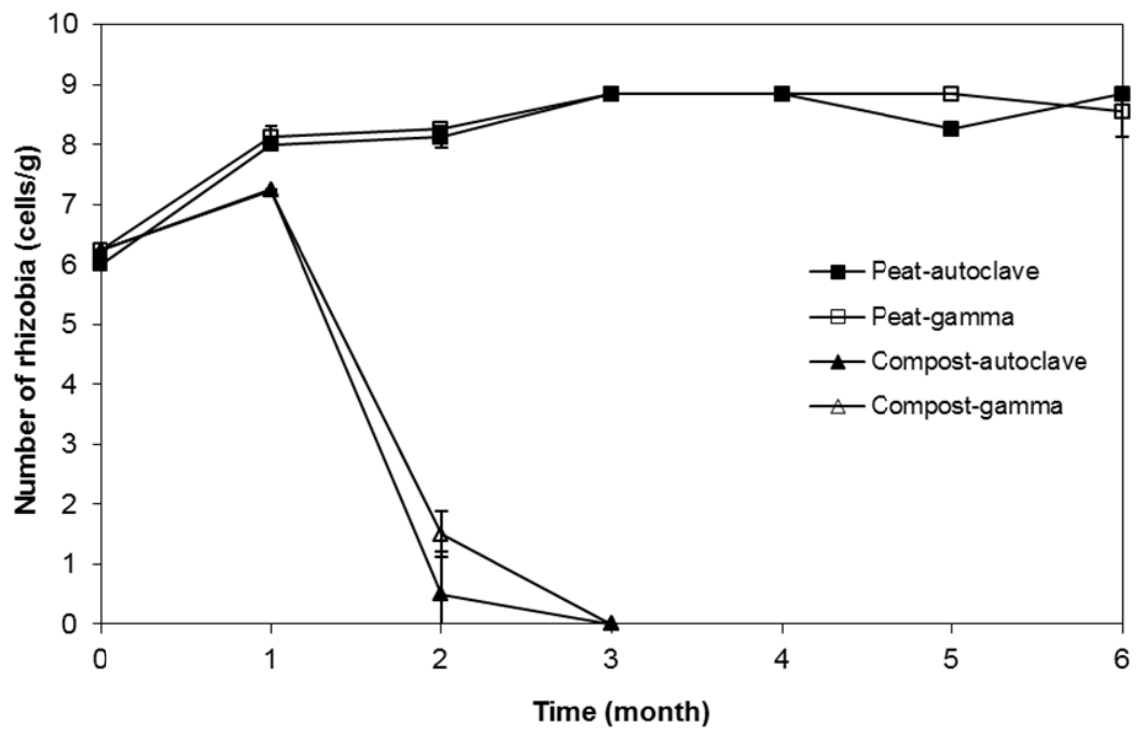

Figure 4. Number of Bradyrhizobium sp. PRC008 surviving in peat with autoclave sterilization (close square), peat with gamma irradiation (open square), compost with autoclave sterilization (close triangle), and compost with gamma irradiation (open triangle) after storage for six months at room temperature

\section{Conclusions}

The carrier material had a significant influence on rhizobial inoculant quality. In this study, compost made from the mixture of cassava peels, filter cake, chicken dung, and cow dung could not be used as carrier instead of peat for bradyrhizobial inoculant production. Nevertheless, the efficient sterilization processes using gamma irradiation and autoclaving with tyndallization approach were elucidated and could be used for sterilization of peat based carrier. The moisture content and types of plastic container affected the gamma dose applied to carrier. The gamma irradiation at dose of $20 \mathrm{kGy}$ could be applied for efficiently minimizing the number of microbial contaminants in peat with $10 \%$ moisture content and packed in PE bag. Moreover, peat with $10 \%$ moisture content could be sterilized by autoclaving two times at $121^{\circ} \mathrm{C}$ for $60 \mathrm{~min}$, with the holding period of $18 \mathrm{~h}$ during each time after autoclaving. By using these two methods, the number of bradyrhizobia remained more than $10^{8}$ cells/g carrier at six months storage at room temperature with good nodulating ability with mungbean seed. 


\section{Acknowledgements}

This research was supported by Suranaree University of Technology and by the Higher Education Research Promotion and National Research University Project of Thailand, Office of the Higher Education Commission. We also thank Thailand Institute of Nuclear Technology for performing the gamma irradiation, and Department of Agriculture (DOA), Thailand for providing peat and rhizobial strain along the experiment.

\section{References}

Abshire, R. L., Bain, B., \& Williams, T. (1980). Resistance and recovery studies on ultraviolet irradiated spores of Bacillus pumilus. Applied Environmental Microbiology, 39, 695-701.

Albareda, M., Rodriguez-Navarro, D. N., Camacho, M., \& Temprano, F. J. (2008). Alternatives to peat as a carrier for rhizobia inoculants: Solid and liquid formulations. Soil Biology and Biochemistry, 40, 2771-2779. http://dx.doi.org/10.1016/j.soilbio.2008.07.021

Brown, J. V., Wiles, R., \& Prentice, G. A. (1979). The effect of a modified Tyndallization process upon the sporeforming bacteria of milk and cream. International Journal of Dairy Technology, 32, 109-112. http://dx.doi.org/10.1111/j.1471-0307.1979.tb01907.x

Cho, H. Y., Yousef, A. E., \& Sastry, S. K. (1999). Kinetics of inactivation of Bacillus subtilis spores by continuous or intermittent ohmic and conventional heating. Biotechnology and Bioengineering, 62, 368-372. $\mathrm{http}: / / \mathrm{dx}$. doi.org/10.1002/(SICI)1097-0290(19990205)62:3<368::AID-BIT14>3.0.CO;2-0

Ferreira, E. M., \& Castro, I. V. (2005). Residues of the cork industry as carriers for the production of legumes inoculants. Silva Lusitana, 13, 159-167.

Gould, G. W. (2006). History of science-spores. Lewis B. Perry Memorial Lecture. Journal of Applied Microbiology, 101, 507-513. http://dx.doi.org/10.1111/j.1365-2672.2006.02888.x

Hansen, J. M., \& Shaffer, H. L. (2001). Sterilization and preservation by radiation sterilization. In S. S. Block (Ed.). Disinfection, sterilization, and preservation (pp. 729-745). Philadelphia: Lippincott Williams \& Wilkins.

Helfinstine, S. L., Vargas-Aburto, C., Uribe, R. M., \& Woolverton, C. J. (2005). Inactivation of Bacillus endospores in envelopes by electron beam irradiation. Applied Environmental Microbiology, 71, 7029-7032. http://dx.doi.org/10.1128/AEM.71.11.7029-7032.200

Khavazi, K., Rejali, F., Seguin, P., \& Miransari, M. (2007). Effects of carrier, sterilization method, and incubation on survival of B. japonicumin soybean (Glycine max L.) inoculants. Enzyme and Microbial Technology, 41, 780-784. http://dx.doi.org/10.1016/j.enzmictec.2007.06.011

Kishore, G. K., Pande, S., \& Podile, A. R. (2005). Phylloplane bacteria increase seedling emergence growth and yield of field-grown groundnut (ArachishypogeaL.). Letters in Applied Microbiology, 40, 260-268. http://dx.doi.org/10.1111/j.1472-765X.2005.01664.x

Oboh, G. (2006). Nutrient enrichment of cassava peels using a mixed culture of Saccharomyces cerevisae and Lactobacillus spp. solid media fermentation techniques. Electronic Journal of Biotechnology, 9. http://dx.doi.org/10.2225/vol9-issue1-fulltext-1

Okon, Y., \& Labandera-Gonzalez, C. A. (1994). Agronomic applications of Azospirillum: an evaluation of 20 years worldwide field inoculation. Soil Biology and Biochemistry, 26, 1591-1601. http://dx.doi.org/10.1016/0038-0717(94)90311-5

Rodriguez-Navarro, D. N., Oliver, I. M., Contreras, M. A., \& Ruiz-Sainz, J. E. (2011). Soybean interactions with soil microbes, agronomical and molecular aspects. Agronomy for Sustainable Development, 31, 173-190. http://dx.doi.org/10.1051/agro/2010023

Smith, R. S. (1992). Legume inoculant formulation and application. Canadian Journal of Microbiology, 38, 485-492. http://dx.doi.org/10.1139/m92-080

Somasegaran, R. J., \& Hoben, H. J. (1994). Handbook for Rhizobia Methods in Legume-Rhizobium Technology. Ann Arbor, USA: Edwards, Inc..

Stephens, J. H., \& Rask, H. M. (2000). Inoculant production and formulation. Field Crops Research, 65, 249-258. http://dx.doi.org/10.1016/S0378-4290(99)00090-8

Strijdom, B. W., \& van Rensburg, H. J. (1981). Effect of stream sterilization and gamma irradiation of peat on quality of Rhizobium inoculants. Applied Environmental Microbiology, 41, 1344-1347. 
Swelim, D. M., Nassef, M. A., \& Elkhatib, E. I. (2010). Survival and shelf life of leguminous trees rhizobia as affected by sterilization, culture dilution and maltose and trace elements enriched carrier. Journal of Applied Science Research, 6, 1366-1372. http://www.aensiweb.com/jasr/jasr/2010/1366-1372.pdf

Tittabutr, P., Payakapong, Teaumroong, W. N., Singleton, P. W., \& Boonkerd, N. (2007). Growth, survival and field performance of bradyrhizobial liquid inoculant formulations with polymeric additives. Science Asia, 33, 69-77. http://dx.doi.org/10.2306/scienceasia1513-1874.2007.33.069

Valero, M., \& Salmeron, M. C. (2003). Antibacterial activity of 11 essential oils against Bacillus cereus in tyndallized carrot broth. International Journal of Food Microbiology, 85, 73-81. http://dx.doi.org/10.1016/S0168-1605(02)00484-1

vanGerwen, S. J. C., Rombouts, F. M., van Riet, K., \& Zwietering, M. H. (1999). A data analysis of the irradiation parameter D for 10 bacteria and spores under various conditions. Journal of Food Protection, 62, 1024-1032.

Yardin, R., Kennedy, I. R., \& Thies, J. E. (2000). Development of high quality carrier materials for field delivery of key microorganisms used as bio-fertilisers and bio-pesticides. Radiation Physics and Chemistry, 57, 565-568. http://dx.doi.org/10.1016/S0969-806X(99)00480-6 